\title{
СТРАТЕГИЯ РАЗВИТИЯ ВОЗДУШНОГО ТРАНСПОРТА В УСЛОВИЯХ ГЛОБАЛИЗАЦИИ МИРОВОЙ ЭКОНОМИКИ
}

\section{STRATEGY FOR THE DEVELOPMENT OF AIR TRANSPORT IN THE GLOBALIZED WORLD ECONOMY}

\author{
S. Demin \\ N. Stolyarov \\ A. Semenova
}

Summary: The article deals with the issues of strategic planning of air transport in the context of globalization. The current planning practice in Russia is compared with the experience of the United States and India. There are bottlenecks in the strategic planning of air transport, in particular, the lack of a strategic audit (control) system. A special place in the article is given to the draft Transport strategy for the period up to 2035, and recommendations are given for finalizing a new version of the Transport strategy.

Keywords: globalization, digitalization, strategic planning, air transport, transport strategy, strategic audit, air transport system, harmonization of regulatory legal regulation of civil aviation.
Демин Сергей Сергеевич ssdemin@mail.ru

Д.э.н., профессор, Московский авиационный институт (национальный исследовательский университет), Москва

Столяров Николай Сергеевич

заслуженный экономист Российской Федерации, д.э.н., профеессор, г.н.С., ФГУП «Государственный научно-исследовательский институт гражданской авиачии», Москва

Семенова Алла Анатольевна Д.э.н., профессор, АНО «Российский новый университет» (РосHОУ), Москва

Аннотация: В статье рассматриваются вопросы стратегического планирования воздушного транспорта в условиях глобализации. Сложившаяся в России практика планирования сравнивается с опытом США и Индии. Отмечаются узкие места в стратегическом планировании воздушного транспорта, в частности, отсутствие системы стратегического аудита (контроля). Особое место в статье уделено проекту Транспортной стратегии на период до 2035 года, даны рекомендации по доработке нового варианта Транспортной стратегии.

Ключевые слова: глобализация, цифровизация, стратегическое планирование, воздушный транспорт, транспортная стратегия, стратегический аудит, авиатранспортная система, гармонизация нормативного правового регулирования гражданской авиации.

гражданскую авиацию. Резкое снижение пассажирских авиаперевозок (от 30\% до 70\% пассажирооборота), в одночасье ставшим критическим финансовое положение многих авиакомпаний, вынужденное сокращение авиапроизводителями выпуска новых самолетов - эти и другие проблемы, вызванные пандемией, лавинообразным потоком нарастают и негативно влияют практически на все сферы экономической жизни страны.

Кризис не вечен, когда-нибудь он с неизбежностью будет преодолен. И уже сегодня нужно смотреть далеко вперед, пытаясь четко определить ориентиры развития гражданской авиации. Важно при этом не оказаться в плену сложившихся и устаревших стереотипов. Вполне очевидно, что гражданская авиация, выйдя из кризиса, уже не будет прежней. Эти ожидания разделяют и руководители авиакомпаний.

Международная ассоциация воздушного транспорта (IATA) сообщила, что 2020 год станет худшим в истории авиаперевозок. В текущем году объем пассажирских авиаперевозок в мире уменьшится на 54,7 процента, количество пассажиров сократится почти в два раза - до 2,25 миллиардов, чистые потери авиакомпаний во всем мире составят около 84 млрд USD (прогноз IATA). Ожи- 
дается, что в 2021 году пассажиропоток вырастет на 55 процентов. При этом он все равно будет на 29 процентов ниже, чем в 2019 году, и дополнительные финансовые потери составят около 15 млрд USD. Таким образом, всего, по оценкам IATA, из-за пандемии авиаперевозчики во всем мире могут потерять до 100 млрд USD. Для сравнения - во время глобального финансового кризиса в 20082009 гг. авиакомпании потеряли 31 млрд USD [15].

Существует, однако, и более пессимистические прогнозы, основанные, на том, что принимаемых для восстановления отрасли мер недостаточно, что в ближайшее время вряд ли удастся изменить возникшее недоверие к воздушному транспорту.

Действительно, должных оснований для радужных прогнозов нет:

- текущее операционные затраты и срочные финансовые обязательства авиакомпаний продолжают расти и на государственную помощь в необходимом объеме при дефиците федерального бюджета рассчитывать не приходиться;

- мировые авиастроители уже заявили, о значительном (на 40\%) сокращении выпуска пассажирских самолетов, и вполне очевидно, что продукция отечественных авиастроителей пока не в состоянии быть конкурентоспособной, чтобы обеспечить потребность в новых самолетах и технологиях; парк воздушных судов России на 73,5 \% представлен зарубежными изделиями, а из остальных $26,5 \%$ половина машин вступила в эксплуатацию еще в советское время;

- система подготовки и переподготовки авиационного персонала, включая современные тренажерные технологии, остается консервативной и неспособной адекватно реагировать на вызовы, порожденные кризисом;

- транспортная доступность малонаселенных и труднодоступных регионов страны все еще остается неразрешимой проблемой, доставшейся в наследство от прошлых времен; для сравнения: в США на 100.000 населения приходится 76,5 самолетов малой авиации, у нас же - всего 3,1.

Перечень проблем гражданской авиации, осложнившихся в условиях кризиса, вызванного пандемией, можно было бы продолжить, но и сказанного достаточно, чтобы сделать вывод: никоим образом не принижая значимость оперативных и тактических (текущих) посткризисных мер, необходимо безотлагательно и на научной основе разработать долгосрочную стратегию развития воздушного транспорта, предусмотрев поэтапное планирование движения к намеченной цели, а именноформированию нового облика гражданской авиации.

Bторое. Новая парадигма стратегии развития воздушного транспорта обусловлена не только (и не столь- ко) стремительно ворвавшейся в нашу жизнь пандемией. Пересмотр ориентиров в области гражданской авиации уже давно назрел и связан с тотальной цифровизацией. «Формирование цифровой экономики - подчеркивает Президент Российской Федерации В.В. Путин, -это вопрос национальной безопасности и независимости России, конкуренции отечественных компаний» [1]. Сегмент цифровых технологий занимает все более значительное место в развитии транспортной инфраструктуры и логистических цепочек и являет собой общемировую тенденцию, характерную и для нашей страны. К сожалению, на сегодняшний день Россия не играет лидирующей роли в этом процессе, однако справедливости ради следует отметить, что за последние годы в нашей стране сделано и многое делается для цифровой трансформации транспортного комплекса. Так, создана Единая государственная информационная система обеспечения транспортной безопасности (ЕГИС ОТБ), позволяющая надежно контролировать пассажирские перевозки - от отдельного пассажира до конкретного транспортного средства. Данная система получила высокую оценку со стороны зарубежных партнеров и признана одной из лучших среди аналогичных систем, используемых в мировой практике.

Компанией «Аэрофлот» испытана и внедрена цифровая технология, позволяющая отслеживать технические состояния агрегатов и узлов воздушного судна во время полета. Огромный поток информации передается в наземную службу технического обслуживания и ремонта и систематизируется в ней. Результат - своевременная замена изношенных деталей, а главное - повышение авиационной безопасности.

Значительных ассигнований потребует цифровая трансформация аэропортов. Аэропорт будущего - это целая экосистема, способная обработать огромное количество данных, свести к минимуму время ожидания в контрольно-пропускных пунктах. Во всем мире спектр услуг, предоставляемых аэропортами, постоянно расширяется. С этой целью логистическо-торговые терминалы превращаются в крупные экономические центры - так называемые аэропорты-города (aerotropolis), способные к комплексному клиентоориентированному обслуживанию пассажиров.

Можно предположить, что уже к 2025 году цифровая трансформация существенно изменит рынок авиаперевозок. К этому времени большинство населения планеты будет представлено постцифровыми поколениями, которые выросли в условиях онлайн-сервисов в быту и привыкли использовать свои мобильные устройства в качестве «пультов управления жизнью». Уже сегодня 54,5\% авиапассажиров используют онлайн-регистрацию через мобильное приложение, сайт, сервисы автоматической регистрации в аэропорту. К 2021 году 79\% ави- 
акомпаний планируют ввести сервисы трекинга (отслеживания) багажа [2].

Разумеется, цифровая трансформация воздушного транспорта не может быть конгломератом отдельных, разрозненных нововведений, а являет собой системное движение в будущее, к новому технологическому укладу, что в свою очередь предполагает системное стратегическое планирование.

Системное стратегическое планирование должно включать:

- финансирование мероприятий цифровой трансформации, включая все источники финансирования, в том числе расходы на НИОКР, субсидий и средств государственного задания, займов и субвенций;

- оценку цифровой зрелости государственных услуг и функций;

- перспективы развития информационных систем, ресурсов и IT-инфраструктуры;

- показатели достижения результативности цифровой трансформации (государственные услуги; контрольно-надзорная функция в сфере транспорта, государственная функция, развитие информационно-телекоммуникационной инфраструктуры и пр).

Tpeтье. Глобализационные процессы последнего десятилетия вносят огромные изменения в мировую систему воздушных перевозок. В стратегии национальной безопасности Российской Федерации, утвержденной Указом президента Российской Федерации № 683 от 31 декабря 2015 года, особо подчеркивается: "Процесс формирования новой политической модели мироустройства сопровождается ростом глобальной и региональной нестабильности. Обостряются противоречия, связанные с неравномерностью мирового развития, углублением разрыва между уровнями благосостояния стран, борьбой за ресурсы, доступом к рынкам сбыта, контролем над транспортными артериями."

Правительства многих стран сделали ставку на поддержку своих ведущих авиаперевозчиков:

- крупнейшая в Европе авиакомпания Lufthansa получит от властей Германии Є9 млрд (около 700 млрд руб.) в обмен на 20\% акций;

- правительство небольшой прибалтийской страны Латвии вложит в уставный капитал авиакомпании Air Baltic €150 млн (около 11,7 млрд. руб.);

- правительство США выделило \$25 млрд. (1,75 трлн руб.) на поддержку крупнейших перевозчиков (частично безвозмездно, частично в виде кредита), в том числе American Airlines получит \$5,8 млрд, Delta Airlines - \$5,4 млрд;

- - на дополнительную антикризисную поддержку российских авиакомпаний правительство выде- лило 23,4 млрд. руб., на поддержку аэропортов - около 10,9 млрд руб. Кроме того, "Аэрофлот" в рамках поддержки системообразующих организаций может получить пятилетние госгарантии для кредитования в банках, в том числе в Сбербанке. Процентная ставка по кредитам, как ожидается, может составить от 6,5 до 7\% годовых. [16]

Таким образом, в условиях глобализации и связанного с нею соперничества мировых держав необходимо умение смотреть далеко вперед, предвидеть последствия происходящих и возможных событий, а в конечном счете - на основе научно обоснованного целеполагания принимать грамотные стратегические решения. Транспортная система, важнейшей составной частью которой является воздушный транспорт, должна соответствовать этой общемировой тенденции.

\section{Г^обализашия и стратегическое п^анирование: зарубежный опыт}

Глобализация - один из самых серьезных вызовов, с которыми столкнулось человечество на исходе XX века. В начале 90-х годов многие ученые заговорили о том, что глобальная экономика принесет не только благоденствие, но и множество кризисов, сопровождающихся тяжелейшими социально-экономическими последствиями для многих миллионов людей. Лауреат Нобелевской премии по рыночной экономике Дж. Стиглиц писал: «Проблема заключается в том, может ли глобализация стать доброй силой, приносящей благо бедным всего мира, - конечно же, она это может. Но ею следует правильно управлять, чего слишком часто не делалось» [3].

Разрушив с началом экономических трансформаций 90-х годов всю систему стратегического планирования централизованного государства, либеральное руководство новой России взяло на вооружение лозунг: «рынок отрегулирует все и вся». Последствия не замедлили сказаться. И, пожалуй, первой пострадала стратегически важная отрасль - гражданская авиация. Иностранные авиапроизводители заполонили рынок своей продукцией, а Россия с неизбежностью утратила статус мировой авиационной державы.

А что же сами Соединенные Штаты Америки? Последовали нашему примеру и свернули свои институты стратегического планирования? Отнюдь. Напротив, значительно усилили их. В январе 1993 года Сенат и Палата представителей Конгресса США приняли закон «О деятельности правительства и его результате» [4], предусматривающий введение стратегического планирования и установки критериев эффективности работы федерального правительства, а также достижение других целей, в частности, «повышать эффективность федеральных программ и публичную отчетность по ним, уделяя большое внимание результатам, качеству услуг и удовлетворе- 
нию потребностей клиентов». В такой постановке закон самым непосредственным образом касался качества транспортных услуг, предоставляемых населению.

В то время, как в нашей стране был упразднен Госплан СССР, федеральный закон США обязывает руководителей каждого ведомства представлять директору Административно-бюджетного управления и Конгрессу стратегический план программных мероприятий, охватывающий период не менее 5 лет с начала финансового года; при этом план обновляется и пересматривается не реже одного раза в три года.

Примечательно, разработку стратегических планов ведомств поручено осуществлять только федеральным служащим.

Доклады об исполнении стратегических планов и программ четко регламентированы: ежегодно (до 31 марта) руководитель каждого ведомства составляет и представляет Президенту и Конгрессу доклад об исполнении программ за предыдущий финансовый год. В каждом докладе даются обзор успешных результатов достижения целей, описания случаев и объяснения причин недостижения целей (несоответствия программного мероприятия критериям успешности).

Контроль за использованием стратегических планов строго регламентирован, для него в рамках контрольно-ревизионной системы существуют функционально независимые контрольные органы, которые инкорпорированы в государственно-правовую систему как необходимый элемент механизма регулирования баланса полномочий исполнительной и законодательной власти США [5].

Небезынтересно будет рассмотреть опыт стратегического планирования в Индии - в стране, где сложился самый быстрорастущий внутренний рынок гражданской авиации в мире. Согласно прогнозам, к 2020 году индийский авиационный рынок станет третьим крупнейшим в мире, а к 2030 году выйдет на первое место в мире по объему. Так, если в 2016 году пассажиропоток в Индии вырос до 180 миллионов человек, то в этом году он составит 370 миллионов человек, при этом 80\% авиационных перевозок будут внутренними.

Причинами столь впечатляющего роста стали не только рост личных доходов граждан, снижение цен на топливо упрощение визового режима и других формальностей. Индийский рынок авиации продемонстрировал устойчивость к глобальному экономическому спаду благодаря проводимой политике, государственному патронажу и планированию.

Ответственность за формулировку национальной политики и программ для развития и регулирования граж- данской авиации возложено на Министерство гражданской авиации правительства Индии.

На протяжении длительного времени в стране работала Плановая комиссия, которая с 1951-1952 г. регулярно составляла пятилетние планы социально-экономического развития страны. Планы определяли параметры экономического роста, капиталовложения как государственного, так и частного секторов. Планирование в отношении государственного сектора отмечалось большой детализацией и носило индикативный характер.

Всего было составлено двенадцать пятилетних планов развития Индии.

В 2015 году правительство Индии заявило о прекращении деятельности Плановой комиссии, главным недостатком работы которой оказалось отсутствие эффективных механизмов взаимодействия центра и штатов, слабый мониторинг и оценка выполнения планов. Внесены были существенные изменения в систему государственного управления - преимущество было отдано методам стратегического планирования. С этой целью было создано новое государственное учреждение - Национальный институт трансформации Индии (НИТИ). Ведомство представляет собой мозговой центр правительства, предназначенный для разработки стратегических и технологических рекомендаций по ключевым вопросам экономики и политики, в том числе и в области гражданской авиации, ориентированной, как уже отмечалось, на развитие внутренних авиаперевозок.

В 2017 году в Индии была принята трехфазная программа структурных изменений экономики, («Лук и стрелы»), затрагивающая непосредственно вопросы развития гражданской авиации. Контроль и координация программы возложены на НИТИ [6].

\section{Проблемы стратегического планирования в Российской ФеАерашии.}

Почти 30 прошло с тех пор, когда в США был принят закон о стратегическом планировании. В это же время В России начались неолиберальные реформы, в результате которых советская система стратегического планирования была упразднена и в последующем утрачена. Даже понятие «планирование» в те времена считалось чем-то предосудительным и неприемлемым для рыночных реформ.

Что мы имеем сегодня? Система стратегического планирования в Российской Федерачии практически отсутствует, чели органов власти не увязываются между собой и с требованиями Президента и Правительства и не стыкуются с проектной деятельностью Правительства, определяются формально, а их достижения не контролируются. Таков неутешительный вывод делаем не 
мы, авторы статьи, а независимый орган государственного аудита (контроля) - Счетная палата Российской Федерации, проведя экспертно- аналитическое мероприятие «Стратегический аудит формирования и достижения показателей деятельности федеральных органов исполнительной власти, руководство деятельностью которых осуществляет Правительство Российской Федерации, в 2017-2018 годах и истекшем периоде 2019 года» [7].

Кроме того, Счетная палата отмечает, что система стратегического планирования деятельности исполнительной власти в настоящее время разбалансирована и неэффективна, недостаточно нормативно урегулирована и методически обеспечена.

В 2014 году был принят федеральный закон «О стратегическом планировании в Российской Федерации» [8]. Однако, он не оправдал надежд и не стал основой системы государственного стратегического планирования. Сегодня стала очевидной необходимость значительных уточнений и доработок закона. А ведь шли к нему почти четверть века!

Можно с полным основанием констатировать, что в настоящее время полноценной системы стратегического планирования не существует: стратегии принимаются без научно обоснованных прогнозов и зачастую носят имитационный характер, стратегический аудит (контроль) за ходом реализации стратегических планов и программ не налажен должным образом, необходимые коррективы и дополнения в принятые стратегии вносятся от случая к случаю, а то и вовсе не вносятся. К сожалению, не является исключением в этом отношении и Транспортная стратегия Российской Федерации.

\section{Транспортная стратегия Российской Федерашии на перио $\Delta$ о 2030 го $\Delta$ а.}

Стратегия была утверждена Распоряжением Правительства Российской Федерации от 22 ноября 2008 года № 1734-p [9].

После почти шестилетнего периода реализации Транспортной стратегии до 2030 года выяснилось, что за эти годы она существенно отстала от реальной практики. Возникла жизненная необходимость ее актуализации и обновления. Что и было сделано.

Новая редакция Транспортной стратегии на период до 2030 года была утверждена Распоряжением Правительства Российской Федерации от 11.06.2014 № 1032p [10]. В 400 страничном документе были составлены два варианта развития: базовый (консервативный) и инновационный.

Предпочтение было отдано второму варианту, который должен способствовать достижению доступно- сти транспортных услуг населению на уровне развитых стран и в соответствии со стандартами безопасности.

Транспортная стратегия, согласно замыслам авторов, должна реализовываться в два этапа: на первом этапе до 2020 года включительно предполагается завершить модернизацию транспортной системы с помощью целевого инвестирования и устранения «узких мест». Затем, с 2021 года по 2030 годы планируется «интенсивное инновационное развитие транспортной системы» для обеспечения, опять-таки, «инновационного» социальноориентированного пути развития Российской Федерачиu.

Особое место в стратегии занимают вопросы развития авиатранспортной системы, на которую был возложен целый ряд задач:

- реконструкция, строительство взлетно-посадочных полос; реконструкция и развитие аэродромов и аэропортовых комплексов, особенно в труднодоступных районах Севера, Сибири, Дальнего Востока и приравненных к ним мест;

- модернизация навигационной системы;

- закупка пассажирских самолетов и стимулирование приобретения воздушных судов российского производства;

- гармонизация нормативно-правового регулирования транспортной деятельности;

- развитие хабовых технологий и совершенствование технологий обслуживания пассажиров;

- повышение доступности авиаперевозок для населения (развитие авиационной подвижности) и др.

Задачи, поистине, амбициозные и по государственному важные. За эти годы многое было сделано для улучшения качества обслуживания авиапассажиров. В 2019 году российские аэропорты обслужили более 221 млн. пассажиров - это наивысший показатель за все 95 лет истории отечественной гражданской авиации. Однако, несмотря на прилагаемые усилия, трудно сказать, что стратегия реализуется успешно. Главную причину, на наш взгляд, следует искать в недостаточном умении прогнозировать на средне - и долгосрочную перспективу, а в дальнейшем грамотно и эффективно доводить идею до логического ее завершения, применяя при этом недооцененный стратегический аудит (контроль), по результатам которого можно было бы корректировать и изменять планы; предугадывать риски, угрозы и вызовы.

Невероятно, но факт: за все время существования Транспортной стратегии (с 2008 года) она ни разу не подвергалась комплексному стратегическому аудиту независимого органа контроля - Счетной палаты Российской Федерации. Согласно федеральному закону «О Счетной палате Российской Федерации» стратегический аудит применяется в целях оценки реализуемости рисков и последствий результатов стратегических целей обеспе- 
чения безопасности и социально-экономического развития Российской Федерации [11] (от 5 апреля 2013 г. №41 -Ф3). Стратегический аудит - это не аудит расходов, а аудит результатов. В зарубежной практике контроля крупных национальных проектов и программ он нашел широкое применение [12].

В 2020 году, согласно Транспортной стратегии Российской Федерации до 2030 года, завершается первый этап ее реализации, результатом которого должен стать переход транспортной системы к ее системному комплексному развитию по всем направлениям, в том числе и в области воздушного транспорта.

На первом этапе должна быть создана «система государственного стратегического планирования в срере транспорта на основе транспортно-экономического баланса и развития статистического наблюдения».

Далее. На первом этапе предполагалось решение вопросов, связанных с ликвидацией «узких мест» в соответствии со стратегиями и концепциями развития видов транспорта. Первый этап завершается (по времени), а долгосрочной стратегии развития воздушного транспорта как не было, так и нет.

Опубликованный Минтрансом 13 июля 2020 доклад о реализации Транспортной стратегии РФ до 2030 г. в отчетном 2019 г. показал, что проблемы, накопленные в сфере транспорта, не только не решаются, но и усугубляются. При этом задачи на будущее становятся все менее масштабными и не ориентированы на кардинальное решение нарастающих проблем. Большинство целей Транспортной стратегии в 2019 г. не было достигнуто. Более чем по половине показателей (47 из 84) целевые значения не были достигнуты - причем эти значения соответствуют наименее амбициозному базовому сценарию. При этом по многим показателям отставание от целевых значений является крайне высоким. В частности, хронически не выполняются планы по строительству и вводу в действие объектов транспортной инфраструктуры, которые измеряются накопленным итогом с 20102011 гг. Так в 2019 году, в сфере воздушного транспорта количество введенных после реконструкции взлетнопосадочных полос составило на 69,9\% меньше, чем запланировано по базовому сценарию и на 71,5%, чем по инновационному сценарию.

При этом, по мнению авторов доклада, основная проблема с невыполнением планов касается того, что значительная доля пассажиров отправляется через Московский авиационный узел. Так доля отправления пассажиров из аэропортов РФ, не входящих в Московский авиационный узел, в общем объеме отправления пассажиров из аэропортов РФ составила на 4,4 \% меньше к обоим сценариям, а средний возраст самолетов вместо 12,3 лет составляет 16,1 года.
Таким образом, стратегическим планам развития всех видов транспорта, в том числе и воздушного, на втором этапе реализации Транспортной стратегии Российской Федерации до 2030 года уже не суждено увидеть свет. Дело в том, что данная стратегия, как и многие ее аналоги, прекратила свое существование на середине пути. Бюрократическим волеизъявлением обновленная стратегия была предана забвению и вместо нее появился проект новой Транспортной стратегии Российской Федерации на период до 2035 года, где нет ни слова о необходимости разработки видовой стратегии - стратегии развития воздушного транспорта.

\section{О проекте Транспортной стратегии Российской Фелерашии на перио $\Delta$ о 2035 года.}

Представляя Правительству Российской Федерации новую транспортную стратегию, М.В. Мишустин так обозначил ее цель - сформулировать современную транспортную инфраструктуру, которая нужна для развития страны и достижения национальных целей. Необходимо задать такую динамику в отрасли, чтобы ее рост опережал запросы других секторов экономики, чтобы люди и бизнес в любой момент могли получить доступные, качественные, новые, технологичные и безопасные услуги» [13].

Чем отличается новая транспортная стратегия от своей предшественницы? Прежде всего объемом (60 страниц), отсутствием излишней детализации, ориентацией на национальные проекты, инновационным характером - одним из наиболее значимых результатов реализации стратегии должно стать внедрение цифровых технологий на всех видах транспорта и транспортной деятельности.

Реализация стратегии предполагается в два этапа. Первый этап реализуется с 2020 по 2024 годы, второй этап - с 2025 по 2035 годы. Уже на первом этапе стратегии ставится задача вхождения российской Федерации в число 5 крупнейших экономик мира и обеспечение темпов экономического роста выше мировых при сохранении макроэкономической стабильности (в том числе инфляции на уровне, не превышающего 4\%). На втором этапе должен быть осуществлен переход к форсированному развитию транспортной системы России.

Для всех видов транспорта, в том числе и воздушного, в Стратегии определены пять главных целей, достижение которых требует реализации целого комплекса задач. В сфере воздушного транспорта, в частности, потребуется:

- реконструкция объектов аэропортовых комплексов:68 объектов -

- к 2024 году и 149 объектов - к 2035 году;

- завершение к 2030 году перехода на электронный документооборот; 
- увеличение авиационной подвижности населения до 0.95 полета

- на 1 человека в год (к 2024 году) и до 1,55 полета на 1 человека в год - к 2035 году);

- повышение уровня защищенности аэропортов от актов незаконного вмешательства.

К 2035 году для реализации мероприятий Стратегии потребуется полное обеспечение воздушными судами отечественного производства нужд региональной и малой авиации, а также авиации общего назначения.

Задачи масштабные, стратегически важные. Для их решения понадобятся значительные материальные ресурсы, эффективное управление, государственный патронаж и контроль.

Успешная реализация Стратегии будет, по замыслу, способствовать связанности территорий России, устойчивости функционирования транспорта как единой отрасли.

Правительство в основном одобрило проект стратегии и отправило его на доработку. А работать есть над чем - и не только потому, что нет пределов в совершенствовании; в документе, на наш взгляд, есть немало «узких мест».

Во-первых, смущает излишний оптимизм документа: все показатели растут, не встречая на своем пути никаких преград. А ведь в неспокойном, стремительно меняющемся мире существует множество угроз и рисков, которые могут весьма серьезно повлиять на реализацию стратегических замыслов. Однако стратегия безальтернативна, из всех возможных сценариев разработчики выбрали самый простой - оптимистичный. Нельзя не помнить, что глобализация имеет не только плюсы, но и минусы. Они хорошо известны. Многие аналитики предсказывают даже конец эпохи глобализации, что с неизбежностью негативно отразится и на состоянии региональных экономик.

Bo-вторых: финансовую нагрузку в интересах достижения стратегических целей и задач разработчики хотят постепенно переложить с государства на пользователей транспортных услуг («пользователь платит»). На наш взгляд, это недальновидная либерализация транспортной системы может значительно осложнить реализацию Стратегии. Это - прежде всего вопрос национальной безопасности. Транспортные артерии страны должны развиваться при активном участии государства и быть под его постоянным контролем.
Один только пример в подтверждение. В прошлом году объем пассажиропотока на внутренних авиалиниях вырос на 7,4\% (по сравнению с предыдущим годом) и составил 135,4 млрд. пассажиро-километров. Этому в значительной мере способствовала долгосрочная государственная политика по реализации программ субсидирования, направленная на увеличение региональных воздушных перевозок, на обеспечение доступности перевозок пассажиров на Дальний Восток, в Симферополь, Калининград и другие регионы страны.

B-mpemьих, нельзя не обратить внимание и на то, что приоритет в стратегии отдан железнодорожному и другим видам транспорта. При всей их значимости нельзя отводить второстепенное место воздушному транспорту, который оказался в весьма затруднительном положении и нуждается в государственной поддержке. Так сравнительный анализ нормативной правовой базы гражданской авиации ИКАО (Международной организации гражданской авиации) и Российской Федерации не в нашу пользу; требуется актуализация всех федеральных авиационных правил, приказов и распоряжений [14]. Система сертификации гражданской авиационной техники нуждается в совершенствовании. Многие эксперты, включая специалистов Счетной палаты Российской Федерации, считают неэффективным исполнение госпрограммы по развитию авиапромышленности Российской Федерации до 2025 года.

B-четвертых, стратегическое управление - это не только планирование, но и анализ, организация, корреляция провозглашенных стратегических целей, контроль. Стратегический аудит (контроль) в органическом единстве с традиционным финансовым аудитом и аудитом эффективности использования располагаемых ресурсов способен обеспечить высокую результативность стратегического управления. К сожалению, в стратегии не только не прописан, но даже не обозначен механизм контроля - ка внутреннего, так и внешнего. Впрочем, это слабое место множества принимаемых и разрабатываемых стратегий.

И, наконец, в-пятых, эффективная реализация целей и задач стратегии, большинство которых носит инновационный характер, невозможна без научного сопровождения, без опоры на науку. Государственный научно-исследовательский институт гражданской авиации (ФГУП ГосНИИ ГА), недавно отметивший свое 90-летие, располагает солидным научно-методическим потенциалом и мог бы взять на себя научное обеспечение реализации Транспортной стратегии Российской Федерации на период до 2035 года. 


\section{ЛИТЕРАТУРА}

1. Путин В.В. Доклад на заседании Совета по стратегическому развитию и приоритетным проектам. - Ново-Огорево, 5 июля 2017 год

2. Шатилин И. Как изменятся авиаперевозки через 5 лет благодаря цифровым технологиям // Frequent Flyers.ru // 23.09.2019.

3. Стиглиц Д.Ю. Ревущие девяностые. Семена раздора. - М.: Современная экономика и право, 2005. С.254.

4. ДОСbE s20.enr - S.20 -S20 Конгресс Соединенных Штатов Америки сто третьего созыва // ДПС МИД РФ, 12.01.97.

5. Демин С.С., Столяров Н.С., Семенова А.А. Опыт организации государственного финансового контроля за рубежом и возможности его применения в России // Актуальные проблемы социально-экономического развития России: научно-аналитический журнал, 2020, №3. - С.14-24.

6. Ростянникова Е.В. От пятилетних планов к стратегическому планированию: опыт Индии. - В кн.: управление социальными инновациями: опыт, проблемы и перспективы. - Москва: РУДН, 2018. - С.23-28.

7. Бюллютень Счетной палаты Российской Федерации, 2020, №1(266).

8. Федеральный закон «0 стратегическом планировании в Российской Федерации» от 28.06.2014 № 172 - Ф3 (ред. От 31.12.2017) // Российское законодательство 2019: Сборник федеральных законов РФ (ФЗ РФ).

9. Транспортная стратегия Российской Федерации на период до 2030 года: Утверждена Распоряжением правительства Российской Федерации от 22 ноября 2008 года №1734-р.

10. Транспортная стратегия Российской Федерации на период до 2030 года: Утверждена Распоряжением правительства Российской Федерации от 11 июня 2014 года №1032-р.

11. Федеральный закон «0 Счетной палате Российской Федерации» от 5 апреля 2013 года №41-Ф3.

12. Столяров Н.С. Финансовый контроль в системе стратегического управления социально-экономическим развитием России (теория и практика). - Монография. - Москва: 2006. - С.309-338.

13. Стенограмма заседания Правительства Российской Федерации, 26 марта 2020 года.

14. Демин С.С., Столяров Н.С., Семенова А.А. Перспективы развития воздушного транспорта в условиях глобализации: монография. - Москва: РуСАЙНС, 2019. $-232 c$.

15. Электронный ресурс. «Рамблер/финансы» (татья: «Эксперты подсчитали потери авиаперевозчиков в 2020 году»; (Дата 0бращения: 14.06.2020); URL: https://finance.rambler.ru/markets/44344873/?utm_content=finance_media\&utm_medium=read_more\&utm_source=copylink

16. Электронный ресурс. «Коммерсантъ. Генрих Костринский «Очередь на вылет. Авиакомпании готовятся к борьбе за выживание»; (Дата обращения: 18.06.2020). URL: https://www.kommersant.ru/doc/4380500?query=\%D0\%B0\%D0\%B2\%D0\%B8\%D0\%B0\%D0\%BA\%D0\%BE\%D0\%BC\%D0\%BF\%D0\%B0\%D0 \%BD\%D0\%B8\%D0\%B8\%20\%D0\%B3\%D0\%BE\%D1\%82\%D0\%BE\%D0\%B2\%D1\%8F\%D1\%82\%D1\%81\%D1\%8F\%20\%D0\%BA\%20\%D0\%B1\%D0\%BE\%D1\%80 \%D1\%8C\%D0\%B1\%D0\%B5\%20\%D0\%B7\%D0\%B0\%20\%D0\%B2\%D1\%8B\%D0\%B6\%D0\%B8\%D0\%B2\%D0\%B0\%D0\%BD\%D0\%B8\%D0\%B5.

( ) Демин Сергей Сергеевич (ssdemin@mail.ru), Столяров Николай Сергеевич, Семенова Алла Анатольевна. Журнал «Современная наука: актуальные проблемы теории и практики» 